\title{
Isochromosome 17q in Chronic Lymphocytic Leukemia
}

\author{
Eyad Alhourani, ${ }^{1}$ Martina Rincic, ${ }^{2}$ Joana B. Melo, ${ }^{3,4}$ Isabel M. Carreira, ${ }^{3,4}$ Anita Glaser, \\ Beate Pohle, ${ }^{1}$ Cordula Schlie, ${ }^{1}$ and Thomas Liehr ${ }^{1}$ \\ ${ }^{1}$ Jena University Hospital, Friedrich Schiller University, Institute of Human Genetics, Kollegiengasse 10, 07743 Jena, Germany \\ ${ }^{2}$ Croatian Institute of Brain Research, Salata 12, 1000 Zagreb, Croatia \\ ${ }^{3}$ Laboratory of Cytogenetics and Genomics, Faculty of Medicine, University of Coimbra, Polo Ciências da Saúde, \\ 3000-548 Coimbra, Portugal \\ ${ }^{4}$ Centro de Investigação em Meio Ambiente, Genética e Oncobiologia (CIMAGO), Polo Ciências da Saúde, \\ 3000-548 Coimbra, Portugal
}

Correspondence should be addressed to Thomas Liehr; thomas.liehr@med.uni-jena.de

Received 25 August 2015; Revised 21 October 2015; Accepted 17 November 2015

Academic Editor: Antonio Cuneo

Copyright (C) 2015 Eyad Alhourani et al. This is an open access article distributed under the Creative Commons Attribution License, which permits unrestricted use, distribution, and reproduction in any medium, provided the original work is properly cited.

\begin{abstract}
In chronic lymphocytic leukemia (CLL), presence of acquired cytogenetic abnormalities may help to estimate prognosis. However, deletion of TP53 gene, which is associated with an aggressive course of the disease and poor prognosis along with a lack of response to treatment, is one of the alterations which may escape cytogenetic diagnoses in CLL. Thus, other techniques have emerged such as interphase fluorescence in situ hybridization (iFISH). Deletion of TP53 may but must not go together with the formation of an isochromosome $\mathrm{i}(17 \mathrm{q})$; surprisingly this subgroup of patients was not in the focus of CLL studies yet. This study was about if presence of $\mathrm{i}(17 \mathrm{q})$ could be indicative for a new subgroup in CLL with more adverse prognosis. As a result, TP53 deletion was detected in 18 out of 150 (12\%) here studied CLL cases. Six of those cases ( 33\%) had the TP53 deletion accompanied by an i(17q). Interestingly, the cases with $\mathrm{i}(17 \mathrm{q})$ showed a tendency towards more associated chromosomal aberrations. These findings may be the bases for follow-up studies in CLL patients with TP53 deletion with and without $\mathrm{i}(17 \mathrm{q})$; it may be suggested that the $\mathrm{i}(17 \mathrm{q})$ presents an even more adverse prognostic marker than TP53 deletion alone.
\end{abstract}

\section{Introduction}

Chronic lymphocytic leukemia (CLL) is a relatively frequently observable acquired disease in men and women of $>50$ years of age [1]. Also CLL is a heterogeneous malignancy, as the survival of CLL patients can be in the range of months to decades according to the underlying genetic abnormalities [2]. The most frequent cytogenetic aberrations in CLL are involving chromosomal subbands $13 \mathrm{q} 14$ (50-60\%), 14q32 (12-15\%), 11q22 (10-20\%), and $17 \mathrm{p} 13(5-10 \%)$ as well as trisomy 12 (15-25\%); each group has different prognoses and survival rates $[1,3]$. Deletion of TP53 gene, which is located in the short arm of chromosome 17 towards the telomeric region in 17p13.1, is associated with poor prognosis and lack of response to fludarabine-based regimens.

TP53 deletion in CLL can be associated with isochromosome formation of the long arm of one chromosome
17 leading at the same time to partial monosomy $17 \mathrm{p}$ and partial trisomy $17 \mathrm{q}$. In general, isochromosome $\mathrm{i}(17 \mathrm{q})$ is the most frequently observed isochromosome in hematological malignancies and it can be present as primary or secondary aberration; that is, it may play roles during development as well as progression of the malignancy. Presence of $i(17 q)$ as a sole abnormality is associated with a high risk of progression and an aggressive clinical course, but $\mathrm{i}(17 \mathrm{q})$ can also be found as part of a complex karyotype [4-6]. In solid tumors, $\mathrm{i}(17 \mathrm{q})$ is reported predominantly in medulloblastoma [7], there often associated with c-myc amplification [8].

Overall, detection of acquired chromosomal abnormalities such as i(17q) just based on GTG-banding may be limited due to low mitotic potential of CLL bone marrow cells. Thus, nowadays other techniques are applied to overcome this problem, by name interphase fluorescence in situ hybridization (iFISH), multiplex ligation dependent probe amplification 
(MLPA), and array-comparative genomic hybridization $(\mathrm{aCGH})[2,9,10]$. Here we studied 150 CLL samples and concentrated on the questions (i) if $\mathrm{i}(17 \mathrm{q})$ can be detected reliably by MLPA and (ii) if $i(17 q)$ presence in patients with TP53 deletion is associated with more complex cytogenetic aberrations. An association with the clinical outcome would have been favorable as well; unfortunately this was not possible due to lack of necessary clinical data.

\section{Material and Methods}

2.1. Patients and Sample Preparation. The present study included 150 CLL patients, which were diagnosed according to standard criteria [11]. The samples were obtained under informed consent of the corresponding patients and according to institutional ethical committee guidelines (Ethical Committee of the Friedrich Schiller University Jena).

DNA was extracted from lymphocytes of 85 CLL cases by a commercial kit (Qiagen) according to manufacturer's instructions. DNA was derived from different sources: 2 samples from heparinized bone marrow, 8 samples from heparinized blood, and 75 samples from cytogenetically prepared cells fixed in methanol/acetic acid $(3: 1)-48$ of them derived from bone marrow and 27 from blood. Details on the studied patients can be found in the paper by Alhourani et al. (2014): the 10 here in more detail studied patients with TP53 deletion (Table 1) were cases 61 (now 1), 1 (now 2), 17 (now 3), 19 (now 4), 12 (now 5), 38 (now 6), 18 (now 7), 16 (now 8), 39 (now 9), and 13 (now 10) from Alhourani et al. (2014) [1]. In the previous study, no special attention was given to the here treated $\mathrm{i}(17 \mathrm{q})$ problem, and additional studies, esp. FISH experiments, and reinterpretation of MLPA and aCGH data were performed here.

For further investigation of $\mathrm{i}(17 \mathrm{q})$ status, additional 65 CLL patients were included in this study with special focus on 8 cases ( 86 to 93 ) with TP53 (Table 1 ).

2.2. GTG-Banding and Interphase-Directed Fluorescence In Situ Hybridization (iFISH) Analysis. GTG-banding and iFISH analyses were done as previously reported [1].

For iFISH, the following probes were used:

(i) Abbott/Vysis (Wiesbaden, Germany): LSI p53/LSI ATM (in 17p13.1 and 11q22.3), LSI D13S319/LSI 13q34/ CEP 12 (in 13q14.3, 13q34, and 12p11.1-q11.1), LSI IGH dual color, break-apart probe (in 14q32.33), LSI SMS Region SpectrumOrange/LSI RARA SpectrumGreen (in 17p11.2 and 17q12-21), CEP 17 (D17Z1 in 17p11.1q11.1), TelVysion 17p (282M16/SP6), and TelVysion 17q (D17S928).

(ii) From Zytovision (Bremerhaven, Germany): ZytoLight SPEC CMYC/CEN 8 Dual Color (8q24.21 and 8p11.1-q11.1).

(iii) BACPAC Resources Center (Oakland, USA): RP11318A15 in 17q25.1 (gene UNC13D) and RP11-94L15 in $17 \mathrm{q} 12$ (gene IKZF3).

For each iFISH analysis, 100-200 interphase nuclei were examined per case and probe.
2.3. Multiplex Ligation Dependent Probe Amplification (MLPA) Analysis. Multiplex ligation dependent probe amplification (MLPA) was performed on 85 CLL cases using SALSA MLPA probemix P377-A1 for Hematological Malignancies Kit from (MRC-Holland, Amsterdam, Netherlands).

The P377-A1 probemix kit contains 52 probes for overall 37 genes; TP53 which is located on the short arm of chromosome 17 is covered by 4 probes; likewise UNC13D and IKZF3 on $\mathrm{q}$ arm were covered by one probe for each of them [1].

2.4. High Resolution Array-Comparative Genomic Hybridization $(a C G H)$. High resolution array-comparative genomic hybridization $(\mathrm{aCGH})$ was performed using Agilent SurePrint G3 Human Genome microarray $180 \mathrm{~K}$ (Agilent Technologies, Santa Clara, CA, USA) as previously reported [12].

\section{Results}

Deletion of TP53 has been detected in 9/85 cases by MLPA. Besides a screening for TP53 deletion was done by iFISH in all of the studied $85 \mathrm{CLL}$ cases to detect mosaic cases with low percentage of aberrant cells as well. Accordingly, TP53 deletion was detected in one additional CLL case, being present there in only $11.5 \%$ of the studied cells (case 10 ).

The overall detected 10 cases with TP53 deletion (Table 2) were further studied by iFISH using probes IKZF3 in 17q12, $U N C 13 D$ in $17 \mathrm{q} 25.1$, and subtelomeric probes (17pter and 17qter; Figure 1(a)); furthermore iFISH-probes for the most frequent aberrations in CLL and, in part, aCGH (case 3; Figure 1(b)) have been applied in those cases, as specified by Alhourani et al. (2014). So, overall 3/85 ( 3.5\%) of here studied CLL cases had the loss of TP53 due to formation of an $\mathrm{i}(17 \mathrm{q})$ which is equal to $30 \%$ of these patients.

Further 8 cases with TP53 deletion were found in additional 65 studied CLL patients by iFISH-probe. Here, subtelomeric (17pter and 17qter) probes were applied to identify the three among them cases with $\mathrm{i}(17 \mathrm{q})$. A probe for 17 p11.2 and 17q12 confirmed the isochromosome status in those cases (Table 3 ).

In the here studied cases with $\mathrm{i}(17 \mathrm{q})$, this alteration was accompanied by additional chromosomal aberrations (Table 4). For all of them, amplification of c-myc was excluded. While in the first 85 CLL patients, cases 1 and 2 were accompanied by five additional acquired chromosomal rearrangements and case 3 had only one additional change. In cases 1 and 2, at least one of these additional changes was correlated with an adverse prognosis; in case 3 the del(13) is considered to be a favorable prognostic factor. Cases 4-10, which showed just deletion of TP53 without isochromosome formation, had either no further aberrations (cases 4 and 9) or just one additional chromosomal alteration associated with good prognosis (cases 5, 7, and 10). Only case 8 showed two additional chromosomal alterations with known adverse prognostic meaning.

Among the 8 cases with TP53 deletion studied only by iFISH, three cases revealed $\mathrm{i}(17 \mathrm{q})$. While case 88 showed 8 additional chromosomal rearrangements (two of them were associated with good prognosis), the other two cases, 86 and 87 , had only one additional chromosomal alteration. 
TABLE 1: Gender, age, and cytogenetic results of the 18 studied CLL cases which showed deletion of TP53 gene.

\begin{tabular}{|c|c|c|c|c|}
\hline Case number & Gender & Age [y] & $\begin{array}{l}\text { DNA extracted } \\
\text { from }\end{array}$ & Banding cytogenetics \\
\hline 1 & $\mathrm{~F}$ & 74 & $\mathrm{bm}$ & $\begin{array}{l}46, \mathrm{XX}, \mathrm{i}(17)(\mathrm{q} 10)[1] / \\
46, \mathrm{XX},+12, \mathrm{i}(17)(\mathrm{q} 10),-21[9] / \\
46, \mathrm{XX}, \mathrm{t}(3 ; ?)(\mathrm{q} 2 ? 9 ; ?)[4],-7[4],+12[4], \mathrm{i}(17)(\mathrm{q} 10)[4][\mathrm{cp} 4] / \\
46, \mathrm{XX}[4]\end{array}$ \\
\hline 2 & M & 83 & bm & $\begin{array}{l}\text { 47,XY,-11,+12,+mar[cp3]/ } \\
\text { 47,XY,del(5)(p1?3),-11,+12,-17,+mar1,+mar2[cp6]/ } \\
46, \mathrm{XY}[9]\end{array}$ \\
\hline 3 & $\mathrm{M}$ & 72 & $\mathrm{bm}$ & $46, \mathrm{XY}$ \\
\hline 4 & $\mathrm{~F}$ & 71 & $\mathrm{~b}$ & $46, \mathrm{XX}$ \\
\hline 5 & $\mathrm{~F}$ & 50 & $\mathrm{~b}$ & n.a. \\
\hline 6 & M & 65 & bm & $\begin{array}{l}46, \mathrm{XY}, ? \mathrm{t}(3 ; ?)(\mathrm{p} 21 ; ?), \operatorname{der}(17) \mathrm{t}(17 ; ?),-18,+\operatorname{mar}[\mathrm{cp} 7] / \\
46, \mathrm{XY}[9]\end{array}$ \\
\hline 7 & $\mathrm{~F}$ & 66 & $\mathrm{~b}$ & n.a. \\
\hline 8 & M & 73 & bm & $\begin{array}{l}\text { 46 47,XY,del(11)(q22q2?3),der(17)t(17;?)(p11.2;?)[cp5]/ } \\
\text { 45 46,XY,del(11)(q22q2?3),del(17)(p11.2)[cp4]/ } \\
\text { 43 46,XY,del(11)(q22q2?3)[cp2]/ } \\
\text { 46,XY[7] }\end{array}$ \\
\hline 9 & $\mathrm{~F}$ & 74 & B & $46, \mathrm{XX}$ \\
\hline 10 & $\mathrm{~F}$ & 90 & $\mathrm{~b}$ & n.a. \\
\hline 86 & M & 74 & n.a. & $\begin{array}{l}45 \sim 46, X Y, i(17)(q 10)[c p 4] / \\
45, X,-Y[2] / \\
46, X Y[14]\end{array}$ \\
\hline 87 & $\mathrm{~F}$ & 76 & n.a. & $\begin{array}{l}\text { 46,XX,?t(6;19)(p22;p13),del(17)(p?11.2)[1] } \\
46, \mathrm{XX}[16]\end{array}$ \\
\hline 88 & M & 65 & n.a. & $\begin{array}{l}\text { 46,XY,t(10;13)(q2?2;q1?3)[10] } \\
\text { 46,XY,i(18)(q10)[1] } \\
\text { 45,XY,?del(6)(?q21),-17[1] } \\
\text { 46,XY,-17,+mar[1] } \\
\text { 44,XY,-11,-17[1] } \\
\text { 46,XY,-4,-21,+2mar[1] } \\
\text { 46,XY[5] }\end{array}$ \\
\hline 89 & $\mathrm{~F}$ & 68 & n.a. & n.a. \\
\hline 90 & $\mathrm{~F}$ & 63 & n.a. & n.a. \\
\hline 91 & $\mathrm{~F}$ & 79 & n.a. & n.a. \\
\hline 92 & $\mathrm{M}$ & 61 & n.a. & n.a. \\
\hline 93 & $\mathrm{~F}$ & 75 & n.a. & n.a. \\
\hline
\end{tabular}

$\mathrm{b}=$ cell pellet in Carnoy's fixative from blood; $\mathrm{bm}=$ cell pellet in Carnoy's fixative from bone marrow; $\mathrm{F}=$ female; $\mathrm{M}=$ male; $\mathrm{n} . \mathrm{a} .=$ not available; $\mathrm{B}=$ native peripheral blood.

The remaining 5 cases with TP53 deletion and no i(17q) were associated with one additional chromosomal aberration with good prognosis (cases 89 and 90 ), or no additional chromosomal changes (cases 91, 92, and 93) (Table 1).

\section{Discussion}

Generally, isochromosome formation is characterized by the loss of the entire short arm with subsequent duplication of the entire long arm, resulting in two homologous arms attached to a single centromere as mirror images $[4,7,13]$. There are two hypotheses to explain the formation of isochromosome, either by transverse instead of longitudinal division of the centromere or by chromatid exchange involving two homologous chromosomes. The rate of the appearance of isochromosomes is different among the various types of tumors, with the highest occurrence in germ cell neoplasms (60\%) and the lowest in chronic myeloproliferative disorders (2.3\%) [14].

Surprisingly, although $\mathrm{i}(17 \mathrm{q})$ appeared in $6 / 150(4 \%)$ here studied CLL patients, that is, and 6/18 ( 33\%) of CLL patients with a deletion of TP53, this chromosomal aberration has not been studied in detail yet in this patient group. Still, there is one study including 2 CLL patients with $\mathrm{i}(17 \mathrm{q})$ which showed that such isochromosome most likely forms due to clustered breakpoints in 17q11 and is not associated with TP53 mutations of the intact chromosome 17 [4]. In 2006, i(17q) was found to be present in 4/16 (25\%) CLL patients with TP53 
TABLE 2: Summary of MLPA and iFISH results of IKZF3- and UNC13D-gene specific probes and subtelomeric probes for chromosome 17 in 10 CLL cases with TP53 deletion in the first group.

\begin{tabular}{|c|c|c|c|c|c|c|c|c|}
\hline \multirow{2}{*}{ Case number } & \multicolumn{2}{|c|}{ TP53 [\%] } & \multicolumn{2}{|c|}{ UNC13D [\%] } & \multicolumn{2}{|c|}{ IKZF3 [\%] } & \multicolumn{2}{|c|}{ iFISH [\%] } \\
\hline & MLPA & iFISH & MLPA & iFISH & MLPA & iFISH & Subtel.pter & Subtel. qter \\
\hline 1 & $\mathrm{~d}$ & $\mathrm{~d}[95]$ & $\mathrm{a}$ & $\mathrm{a}[90]$ & $\mathrm{a}$ & $\mathrm{a}[90]$ & $\mathrm{d}[90]$ & $\mathrm{a}[90]$ \\
\hline 2 & $\mathrm{~d}$ & $\mathrm{~d}[40]$ & a & $\mathrm{a}[40]$ & $\mathrm{a}$ & $\mathrm{a}[40]$ & $\mathrm{d}[40]$ & $\mathrm{a}[40]$ \\
\hline 3 & $\mathrm{~d}$ & $\mathrm{~d}[40]$ & $\mathrm{n}$ & $\mathrm{a}[25]$ & $\mathrm{n}$ & $\mathrm{a}[25]$ & $\mathrm{d}[25]$ & $\mathrm{a}[25]$ \\
\hline 4 & $\mathrm{~d}$ & $\mathrm{~d}[36]$ & $\mathrm{n}$ & $\mathrm{n}$ & $\mathrm{n}$ & $\mathrm{n}$ & $\mathrm{n}$ & $\mathrm{n}$ \\
\hline 5 & $\mathrm{~d}$ & $\mathrm{~d}[21]$ & $\mathrm{n}$ & $\mathrm{n}$ & $\mathrm{n}$ & $\mathrm{n}$ & $\mathrm{n}$ & $\mathrm{n}$ \\
\hline 6 & $\mathrm{~d}$ & d [89] & $\mathrm{n}$ & $\mathrm{n}$ & $\mathrm{n}$ & $\mathrm{n}$ & $\mathrm{n}$ & $\mathrm{n}$ \\
\hline 7 & $\mathrm{~d}$ & d [19] & $\mathrm{n}$ & $\mathrm{n}$ & $\mathrm{n}$ & $\mathrm{n}$ & $\mathrm{n}$ & $\mathrm{n}$ \\
\hline 8 & $\mathrm{~d}$ & $\mathrm{~d}[86]$ & $\mathrm{n}$ & $\mathrm{n}$ & $\mathrm{n}$ & $\mathrm{n}$ & $\mathrm{n}$ & $\mathrm{n}$ \\
\hline 9 & d & d [77] & $\mathrm{n}$ & $\mathrm{n}$ & $\mathrm{n}$ & $\mathrm{n}$ & $\mathrm{n}$ & $\mathrm{n}$ \\
\hline 10 & $\mathrm{n}$ & $\mathrm{d}[11,5]$ & $\mathrm{n}$ & $\mathrm{n}$ & $\mathrm{n}$ & $\mathrm{n}$ & $\mathrm{n}$ & $\mathrm{n}$ \\
\hline 11 to 85 & $\mathrm{n}$ & $\mathrm{n}$ & $\mathrm{n}$ & n.a. & $\mathrm{n}$ & n.a. & n.a. & n.a. \\
\hline
\end{tabular}

$\mathrm{n}=$ no aberration, $\mathrm{d}=$ deletion, $\mathrm{a}=$ amplification, $\mathrm{n} . \mathrm{a} .=$ not tested, and [] = percentage of cells with aberration.

TABLE 3: Summary of iFISH results using SMS and RARA gene specific probes and subtelomeric probes for chromosome 17 in $8 \mathrm{CLL}$ cases with TP53 deletion in CLL cases only studied by iFISH and not by MLPA.

\begin{tabular}{lccccc}
\hline \multirow{2}{*}{ Case number } & iFISH [\%] & \multicolumn{2}{c}{ iFISH [\%] } & \multicolumn{2}{c}{ iFISH [\%] } \\
& TP53 & Subtel. pter & Subtel. qter & SMS & RARA \\
\hline 86 & $\mathrm{~d}[77]$ & $\mathrm{d}[77]$ & $\mathrm{a}[77]$ & $\mathrm{d}[77]$ & $\mathrm{a}[77]$ \\
87 & $\mathrm{~d}[77]$ & $\mathrm{d}[77]$ & $\mathrm{a}[77]$ & $\mathrm{d}[77]$ & $\mathrm{a}[77]$ \\
88 & $\mathrm{~d}[80]$ & $\mathrm{d}[80]$ & $\mathrm{a}[80]$ & $\mathrm{d}[80]$ & $\mathrm{a}[80]$ \\
89 & $\mathrm{~d}[69]$ & $\mathrm{n}$ & $\mathrm{n}$ & n.a & n.a \\
90 & $\mathrm{~d}[28]$ & $\mathrm{n}$ & $\mathrm{n}$ & n.a & n.a \\
91 & $\mathrm{~d}[75]$ & $\mathrm{n}$ & $\mathrm{n}$ & n.a & n.a \\
92 & $\mathrm{~d}[89]$ & $\mathrm{n}$ & $\mathrm{n}$ & n.a & n.a \\
93 & $\mathrm{~d}[95.5]$ & $\mathrm{n}$ & $\mathrm{n}$ & n.a & n.a \\
94 to 150 & $\mathrm{n}$ & $\mathrm{n} . \mathrm{a}$ & n.a & n.a & n.a \\
\hline
\end{tabular}

$\mathrm{n}=$ no aberration, $\mathrm{d}=$ deletion, $\mathrm{a}=$ amplification, $\mathrm{n} . \mathrm{a} .=$ not tested, and $[\mathrm{]}=$ percentage of cells with aberration.

gene loss [15]; that is, the here reported frequency is within the same range. However, the initial finding of an $i(17 q)$ in $2 / 21$ (9.5\%) CLL cases seems to be overestimated due to small sample size [16].

Even though here only 6 cases with $\mathrm{i}(17 \mathrm{q})$ could be studied, the results summarized in Table 4 show a clear tendency: cases with $\mathrm{i}(17 \mathrm{q})$ are associated with more aberrations compared to those which have just deletion of TP53. Cases 3 and 8 do not exactly fit into this suggestion. However, case 3 had only $25 \%$ of the cells with an $\mathrm{i}(17 \mathrm{q})$ indicating an early phase of the disease; in case 8 cytogenetics provided a hint on an ongoing karyotypic evolution and already advanced stage of the disease.

Whereas both Baliakas et al. and Rigolin et al. reported that complex karyotype predicts a worse overall survival, also Baliakas et al. demonstrated that complex karyotype is identified as an independent prognostic factor for shorter time-to-first-treatment $[17,18]$.
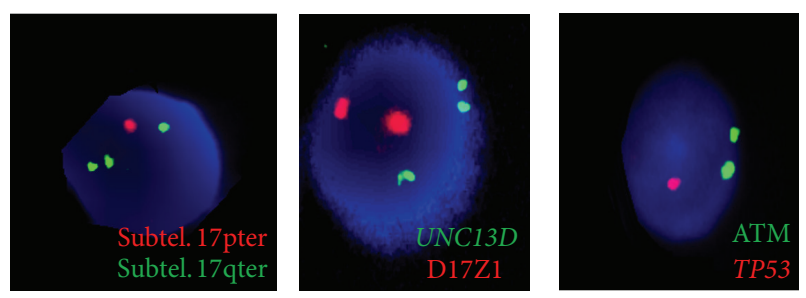

(a)

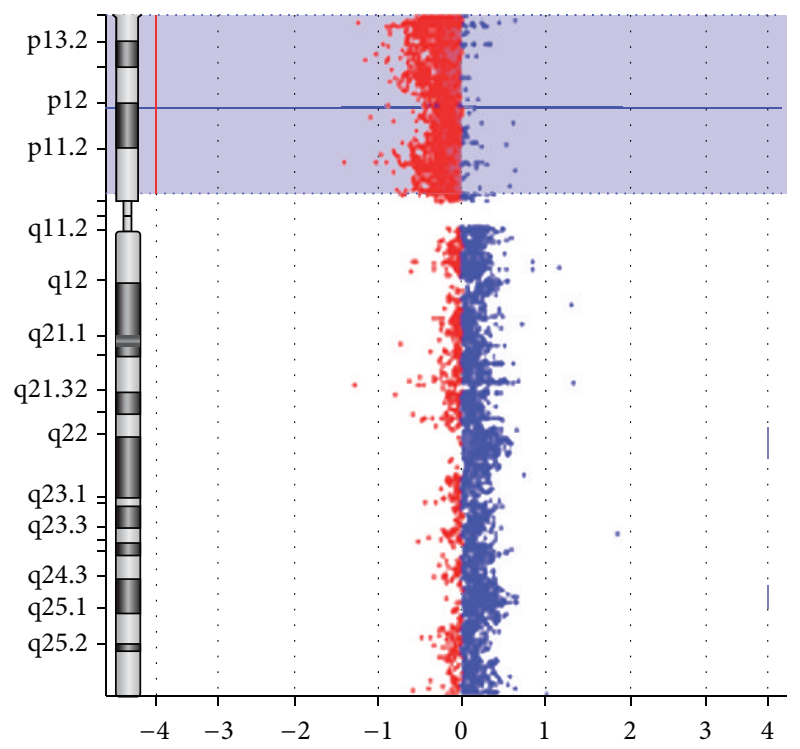

(b)

FIGURE 1: (a) Isochromosome $17 \mathrm{q}$ was detected initially by iFISH in this case; representative examples for heterozygote deletions of TP53 and \#17 subtelomeric region 17p (subtel. 17pter) besides three signals for UNC13D and subtel. 17qter. Only 2 signals for centromere of chromosome 17 (D17Z1) and ATM gene on chromosome 11 were detected. (b) aCGH showed deletion of short arm and gain of long arm of chromosome 17 in case 3.

Furthermore, Thompson et al. showed that relapsed/ refractory CLL patients who reveal $\operatorname{del}(17 p)$ and complex 


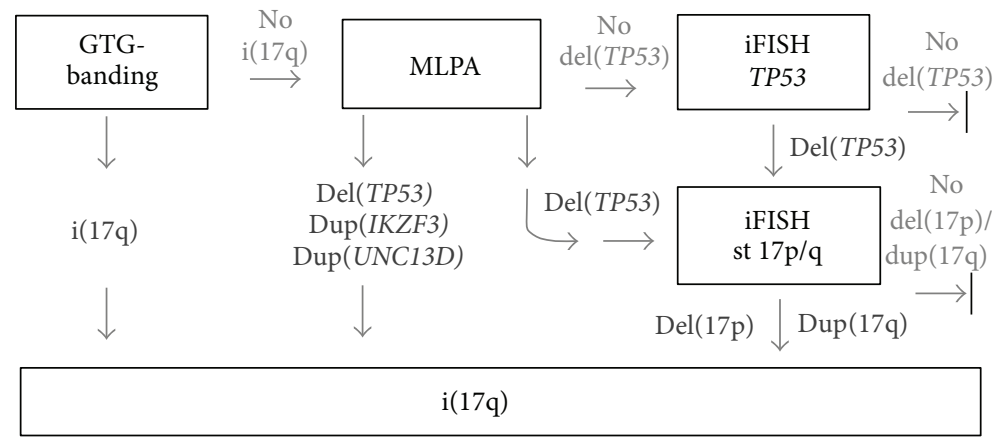

FIGURE 2: Here a scheme for the suggested procedures how to delineate an i(17q), if cytogenetics, MLPA, and iFISH are available.

TABLE 4: All 18 CLL cases which revealed TP53 deletion are listed showing the additionally detected chromosomal aberrations and their clinical impact (1).

\begin{tabular}{|c|c|c|}
\hline Case number & $\begin{array}{l}\text { Additional aberrations } \\
\text { not listing \#17 aberrations [\%] }\end{array}$ & Prognosis \\
\hline \multirow{5}{*}{1} & $\mathrm{t}(3 ; ?)(\mathrm{q} 2 ? 9 ; ?)[22]$ & n.a. \\
\hline & $-7[22]$ & Adverse \\
\hline & $+12[78]$ & Intermediate \\
\hline & $\operatorname{del}(14)(q 32 q 32)[94]$ & Good \\
\hline & $-21[50]$ & n.a. \\
\hline \multirow{5}{*}{2} & $\operatorname{del}(5)(\mathrm{p} 1 ? 3)[33]$ & n.a. \\
\hline & $\operatorname{del}(11)(q 22.3 q 22.3)[30]$ & Adverse \\
\hline & $+12[70]$ & Intermediate \\
\hline & $\operatorname{del}(13)(q 14.3 q 14.3)[30]$ & Good \\
\hline & $\operatorname{rea}(14)(q 32.33)[28]->?+14$ & Adverse \\
\hline 3 & $\operatorname{del}(13)(\mathrm{q} 14.3 \mathrm{q} 14.3)[20]$ & Good \\
\hline 4 & None detected & Intermediate \\
\hline \multirow{3}{*}{5} & $\operatorname{del}(13)(q 14.2 q 14.2)[52]$ & \\
\hline & $\operatorname{del}(13)(\mathrm{q} 14.2 \mathrm{q} 14.2) \times 2[38]$ & Good \\
\hline & $\operatorname{del}(13)(\mathrm{q} 14.3 \mathrm{q} 14.3)[34]$ & \\
\hline \multirow{2}{*}{6} & $\mathrm{t}(3 ; ?)(\mathrm{p} 21 ; ?)[44]$ & n.a. \\
\hline & $-18,+\operatorname{mar}[44]$ & n.a. \\
\hline 7 & $\operatorname{del}(13)(\mathrm{q} 14.3 \mathrm{q} 14.3)[90.5]$ & Good \\
\hline \multirow{2}{*}{8} & $\operatorname{amp}(8)(\mathrm{q} 24.21 \mathrm{q} 24.21)[21]$ & Adverse \\
\hline & $\operatorname{del}(11)(\mathrm{q} 22.3 \mathrm{q} 22.3)[11]$ & Adverse \\
\hline 9 & None detected & Intermediate \\
\hline 10 & $\operatorname{del}(13)(\mathrm{q} 14.3 \mathrm{q} 14.3) \times 2[98.5]$ & Good \\
\hline 86 & $-\mathrm{Y}$ & n.a. \\
\hline 87 & $? \mathrm{t}(6 ; 19)(\mathrm{p} 22 ; \mathrm{p} 13), \operatorname{del}(17)(\mathrm{p} ? 11.2)$ & Adverse \\
\hline \multirow{8}{*}{88} & $\mathrm{t}(10 ; 13)(\mathrm{q} 2 ? 2 ; \mathrm{q} 1 ? 3)$ & Advesrse \\
\hline & $\mathrm{i}(18)(\mathrm{q} 10)$ & n.a. \\
\hline & $? \operatorname{del}(6)(? q 21),-17$ & n.a. \\
\hline & $-17,+\operatorname{mar}$ & n.a. \\
\hline & $-11,-17$ & n.a. \\
\hline & $-4,-21,+2 \mathrm{mar}$ & n.a. \\
\hline & $\operatorname{del}(13)(q 14.3 q 14.3)[57]$ & Good \\
\hline & $\operatorname{del}(14)(\mathrm{q} 32 \mathrm{q} 32)[75]$ & Good \\
\hline \multirow{2}{*}{89} & $\operatorname{del}(13)(q 14.2 q 14.2)[50]$ & \multirow{2}{*}{ Good } \\
\hline & $\operatorname{del}(13)(\mathrm{q} 14.2 \mathrm{q} 14.2) \times 2[7]$ & \\
\hline 90 & $\operatorname{del}(14)(\mathrm{q} 32 \mathrm{q} 32)[36]$ & Good \\
\hline 91 & None detected & Intermediate \\
\hline 92 & None detected & Intermediate \\
\hline 93 & None detected & Intermediate \\
\hline
\end{tabular}

n.a. = not available. karyotype have shorter overall survival than those with only $\operatorname{del}(17 p)[19]$.

Due to lack of clinical data, the clinical impact of $i(17 q)$ could not be followed up, but in spite of that the present study gives first hints that $\mathrm{i}(17 \mathrm{q})$ presence may be an indicator for more aggressive course of CLL disease than just TP53 deletion without $\mathrm{i}(17 \mathrm{q})$ formation. Similar findings were reported for other hematological neoplasia, like acute lymphocytic leukemia [20], acute promyelocytic leukemia [21], chronic myeloid leukemia [5], or other myeloid leukemia [22-24].

As previously outlined by us and others, MLPA is a quick and inexpensive screening tool for CLL diagnostics $[1,25]$. However, its inability to detect low level mosaics needs to be considered and thus a diagnostic scheme combining cytogenetics, iFISH, and MLPA needs to be considered for reliable testing of CLL cases in diagnostics [1]. Thus, in Figure 2 we suggest a scheme of how to detect $\mathrm{i}(17 \mathrm{q})$ reliably.

In conclusion, $\mathrm{i}(17 \mathrm{q})$ presence in CLL cases with TP53 deletion should be considered as a potentially adverse marker for more aggressive course of the disease than monosomy of 17 p13.1 alone; it needs to be kept in mind that MLPA alone may be not sufficient to pick up all corresponding cases and a combination with iFISH may be considered additionally.

\section{Conflict of Interests}

The authors declare that they have no competing interests.

\section{Acknowledgment}

This paper was supported in part by the KAAD.

\section{References}

[1] E. Alhourani, M. Rincic, M. A. Othman et al., "Comprehensive chronic lymphocytic leukemia diagnostics by combined multiplex ligation dependent probe amplification (MLPA) and interphase fluorescence in situ hybridization (iFISH)," Molecular Cytogenetics, vol. 7, no. 1, article 79, 2014.

[2] A. E. Rodríguez-Vicente, M. G. Díaz, and J. M. HernándezRivas, "Chronic lymphocytic leukemia: a clinical and molecular heterogenous disease," Cancer Genetics, vol. 206, no. 3, pp. 4962, 2013.

[3] H. Döhner, S. Stilgenbauer, A. Benner et al., "Genomic aberrations and survival in chronic lymphocytic leukemia," The New England Journal of Medicine, vol. 343, no. 26, pp. 1910-1916, 2000 . 
[4] T. Fioretos, B. Strömbeck, T. Sandberg et al., "Isochromosome $17 \mathrm{q}$ in blast crisis of chronic myeloid leukemia and in other hematologic malignancies is the result of clustered breakpoints in 17p11 and is not associated with coding TP53 mutations," Blood, vol. 94, no. 1, pp. 225-232, 1999.

[5] R. F. McClure, G. W. Dewald, J. D. Hoyer, and C. A. Hanson, "Isolated isochromosome 17q: a distinct type of mixed myeloproliferative disorder/myelodysplastic syndrome with an aggressive clinical course," British Journal of Haematology, vol. 106, no. 2, pp. 445-454, 1999.

[6] R. Kanagal-Shamanna, C. E. Bueso-Ramos, B. Barkoh et al., "Myeloid neoplasms with isolated isochromosome 17q represent a clinicopathologic entity associated with myelodysplastic/myeloproliferative features, a high risk of leukemic transformation, and wild-type TP53," Cancer, vol. 118, no. 11, pp. 2879-2888, 2012.

[7] W. G. Scheurlen, G. C. Schwabe, P. Seranski et al., "Mapping of the breakpoints on the short arm of chromosome 17 in neoplasms with an i(17q)," Genes Chromosomes and Cancer, vol. 25, no. 3, pp. 230-240, 1999.

[8] K. D. Wright, K. von der Embse, J. Coleman, Z. Patay, D. W. Ellison, and A. Gajjar, "Isochromosome 17q, MYC amplification and large cell/anaplastic phenotype in a case of medullomyoblastoma with extracranial metastases," Pediatric Blood \& Cancer, vol. 59, no. 3, pp. 561-564, 2012.

[9] D. P. O’Malley, C. Giudice, A. S. Chang et al., "Comparison of array comparative genomic hybridization (aCGH) to FISH and cytogenetics in prognostic evaluation of chronic lymphocytic leukemia," International Journal of Laboratory Hematology, vol. 33, no. 3, pp. 238-244, 2011.

[10] L. Véronèse, O. Tournilhac, P. Combes et al., "Contribution of MLPA to routine diagnostic testing of recurrent genomic aberrations in chronic lymphocytic leukemia," Cancer Genetics, vol. 206, no. 1-2, pp. 19-25, 2013.

[11] M. Hallek, B. D. Cheson, D. Catovsky et al., "Guidelines for the diagnosis and treatment of chronic lymphocytic leukemia: a report from the International Workshop on Chronic Lymphocytic Leukemia updating the National Cancer InstituteWorking Group 1996 guidelines," Blood, vol. 111, no. 12, pp. 5446-5456, 2008.

[12] M. A. Othman, M. Rincic, J. B. Melo et al., "A novel cryptic three-way translocation $\mathrm{t}(2 ; 9 ; 18)(\mathrm{p} 23.2 ; \mathrm{p} 21.3 ; \mathrm{q} 21.33)$ with deletion of tumor suppressor genes in 9p21.3 and 13q14 in a Tcell acute lymphoblastic leukemia," Leukemia Research and Treatment, vol. 2014, Article ID 357123, 7 pages, 2014.

[13] J.-C. Hernández-Boluda, F. Cervantes, D. Costa, A. Carrió, and E. Montserrat, "Blast crisis of Ph-positive chronic myeloid leukemia with isochromosome 17q: report of 12 cases and review of the literature," Leukemia \& Lymphoma, vol. 38, no. 1-2, pp. 83-90, 2000.

[14] F. Mertens, B. Johansson, and F. Mitelman, "Isochromosomes in neoplasia," Genes Chromosomes and Cancer, vol. 10, no. 4, pp. 221-230, 1994.

[15] S. R. Fink, S. A. Smoley, K. J. Stockero et al., "Loss of TP53 is due to rearrangements involving chromosome region 17p10 p12 in chronic lymphocytic leukemia," Cancer Genetics and Cytogenetics, vol. 167, no. 2, pp. 177-181, 2006.

[16] M. Vahdati, H. Graafland, and J. M. Emberger, "Karyotype analysis of B-lymphocytes transformed by Epstein-Barr virus in 21 patients with B cell chronic lymphocytic leukemia," Human Genetics, vol. 63, no. 4, pp. 327-331, 1983.
[17] G. Rigolin, I. del Giudice, L. Formigaro et al., "Chromosome aberrations detected by conventional karyotyping using novel mitogens in chronic lymphocytic leukemia: clinical and biologic correlations," Genes, Chromosomes and Cancer, vol. 54, no. 12, pp. 818-826, 2015.

[18] P. Baliakas, M. Iskas, A. Gardiner et al., "Chromosomal translocations and karyotype complexity in chronic lymphocytic leukemia: a systematic reappraisal of classic cytogenetic data," American Journal of Hematology, vol. 89, no. 3, pp. 249-255, 2014.

[19] P. A. Thompson, S. M. O’Brien, W. G. Wierda et al., "Complex karyotype is a stronger predictor than del(17p) for an inferior outcome in relapsed or refractory chronic lymphocytic leukemia patients treated with ibrutinib-based regimens," Cancer, vol. 121, no. 20, pp. 3612-3621, 2015.

[20] C.-H. Pui, S. C. Raimondi, and D. L. Williams, "Isochromosome $17 \mathrm{q}$ in childhood acute lymphoblastic leukemia: an adverse cytogenetic feature in association with hyperdiploidy?" Leukemia, vol. 2, no. 4, pp. 222-225, 1988.

[21] D. Yanchao, N. Jing, Z. Zhirong et al., "A rare case with typical acute promyelocytic leukemia morphology associated with isolated isochromosome 17q without RAR $\alpha$ rearrangement," Hematology/Oncology and Stem Cell Therapy, vol. 6, no. 1, pp. 42-45, 2013.

[22] R. Becher, F. Carbonell, and C. R. Bartram, "Isochromosome 17q in Ph1-negative leukemia: a clinical, cytogenetic, and molecular study," Blood, vol. 75, no. 8, pp. 1679-1683, 1990.

[23] J. C. Sousa, R. T. Germano, C. C. Castro, S. M. Magalhaes, and R. F. Pinheiro, "Case report of isochromosome $17 \mathrm{q}$ in acute myeloid leukemia with myelodysplasia-related changes after treatment with a hypomethylating agent," Genetics and Molecular Research, vol. 11, no. 3, pp. 2045-2050, 2012.

[24] E. You, S. Y. Cho, J. J. Yang et al., "A novel case of extreme thrombocytosis in acute myeloid leukemia associated with isochromosome 17q and copy neutral loss of heterozygosity," Annals of Laboratory Medicine, vol. 35, no. 3, pp. 366-369, 2015.

[25] C. Hömig-Hölzel and S. Savola, "Multiplex Ligation-dependent Probe Amplification (MLPA) in tumor diagnostics and prognostics," Diagnostic Molecular Pathology, vol. 21, no. 4, pp. 189206, 2012. 


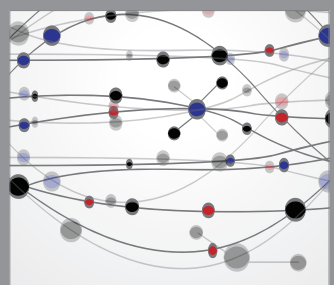

The Scientific World Journal
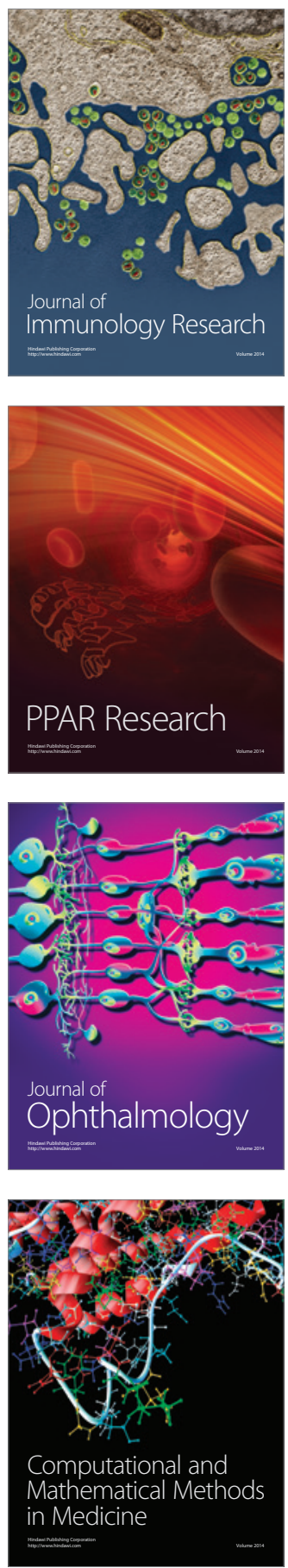

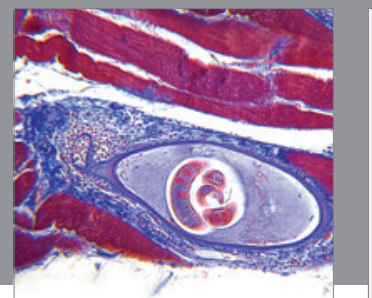

Gastroenterology

Research and Practice
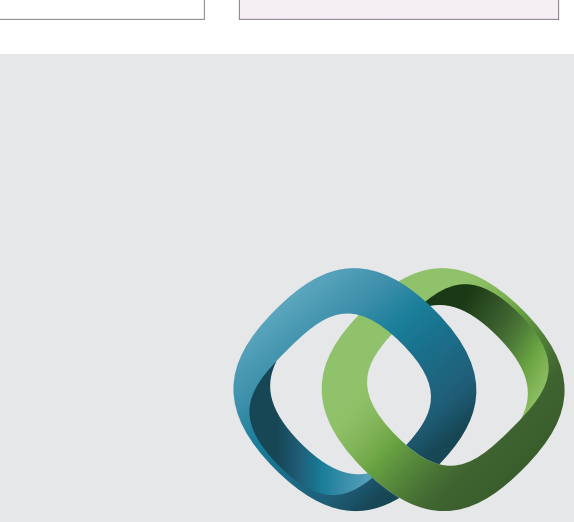

\section{Hindawi}

Submit your manuscripts at

http://www.hindawi.com
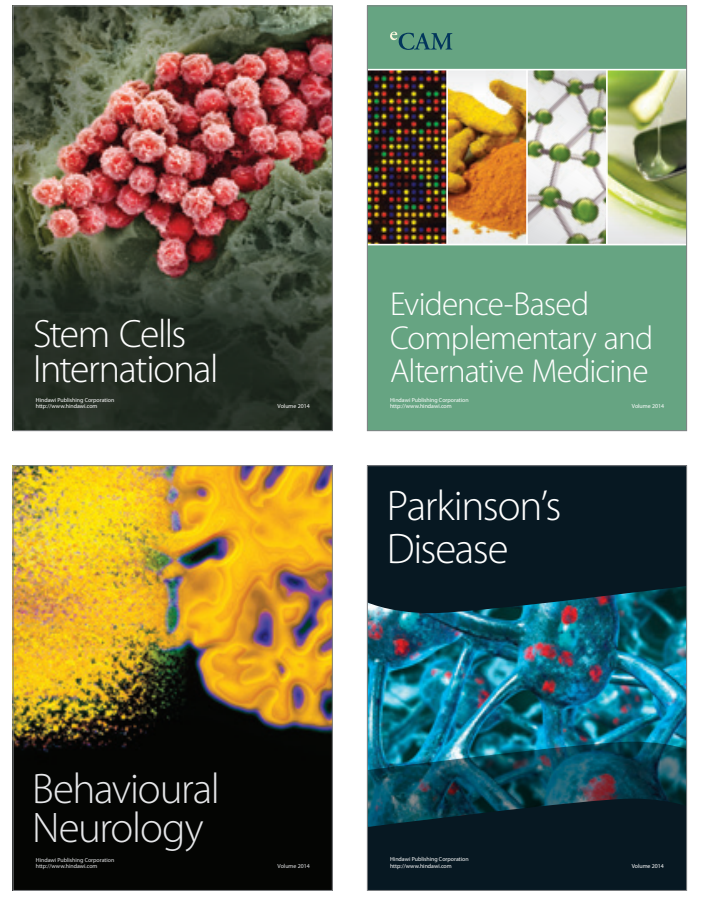
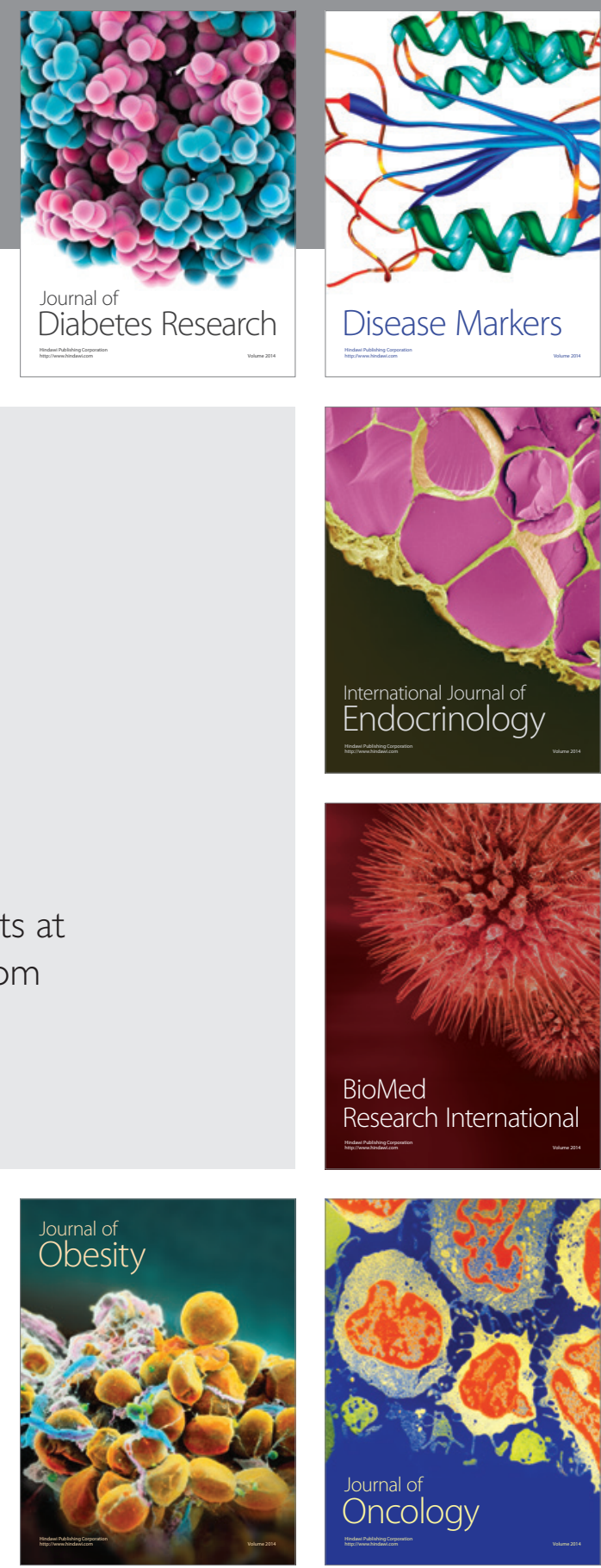

Disease Markers
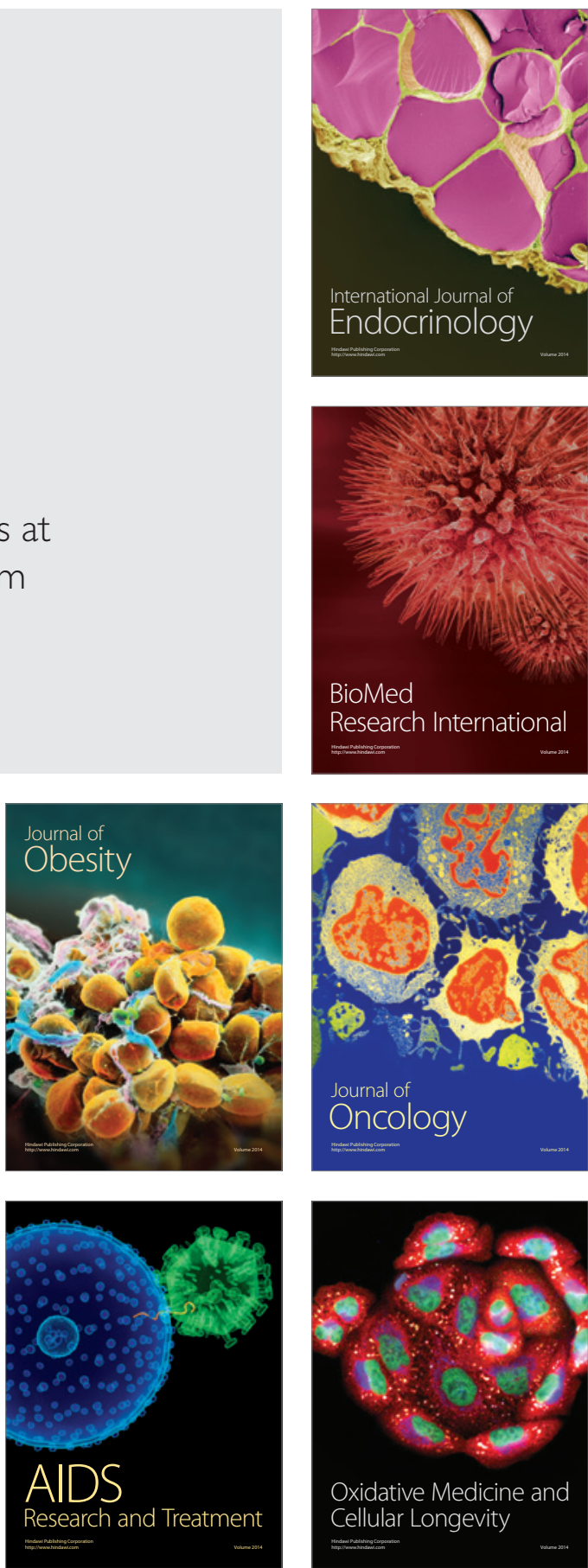